IZA DP No. 329

Wage Differentials and Mbbility in the Urban Labor Market: A Panel Data Analysis for Mexico

Xiaodong Gong

Arthur van Soest

J uly 2001 


\title{
Wage Differentials and Mobility in the Urban Labor Market: A Panel Data Analysis for Mexico
}

\author{
Xiaodong Gong
}

IZA, Bonn

\author{
Arthur van Soest \\ Tilburg University
}

\author{
Discussion Paper No. 329 \\ July 2001 \\ IZA \\ P.O. Box 7240 \\ D-53072 Bonn \\ Germany \\ Tel.: +49-228-3894-0 \\ Fax: +49-228-3894-210 \\ Email: iza@iza.org
}

This Discussion Paper is issued within the framework of IZA's research area Mobility and Flexibility of Labor Markets. Any opinions expressed here are those of the author(s) and not those of the institute. Research disseminated by IZA may include views on policy, but the institute itself takes no institutional policy positions.

The Institute for the Study of Labor (IZA) in Bonn is a local and virtual international research center and a place of communication between science, politics and business. IZA is an independent, nonprofit limited liability company (Gesellschaft mit beschränkter Haftung) supported by the Deutsche Post AG. The center is associated with the University of Bonn and offers a stimulating research environment through its research networks, research support, and visitors and doctoral programs. IZA engages in (i) original and internationally competitive research in all fields of labor economics, (ii) development of policy concepts, and (iii) dissemination of research results and concepts to the interested public. The current research program deals with (1) mobility and flexibility of labor markets, (2) internationalization of labor markets and European integration, (3) the welfare state and labor markets, (4) labor markets in transition, (5) the future of work, (6) project evaluation and (7) general labor economics.

IZA Discussion Papers often represent preliminary work and are circulated to encourage discussion. Citation of such a paper should account for its provisional character. 
IZA Discussion Paper No. 329

July 2001

\section{ABSTRACT \\ Wage Differentials and Mobility in the Urban Labor Market: A Panel Data Analysis for Mexico}

We analyze wage differentials mobility between the formal and informal sector in urban Mexico, using panel data on five quarters drawn from Mexico's Urban Employment Survey. We develop a dynamic random effects panel data model. It consists of two separate wage equations for the two sectors and a multinomial logit part explaining the labor market state, in which wages are included as explanatory variables. The model is estimated using simulated maximum likelihood. The estimates show that wage differentials increase with education level. The probability of formal sector employment strongly increases with the wage differential. Simulated transition probabilities show that for male workers, the choice between formal and informal sector is driven by wage differentials and unobserved heterogeneity, while true state dependence is much less important. For women, nonparticipation is the most common labour market state, and true state dependence plays a much larger role.

JEL Classification: $\quad$ C33, J23, J31, R23

Keywords: Wage differentials, informal sector, mobility, panel data, Mexico

Xiaodong Gong

IZA

P.O. Box 7240

53072 Bonn

Germany

Tel.: +49 228/ 3894527

Fax: +49 228/ 3894510

Email: gong@iza.org 


\section{Introduction}

In countries with a large informal sector, the nature of the informal sector and its position compared to the formal sector are crucial for the functioning of the labor market and the overall economic structure. It affects, for example, income inequality and poverty, it has implications for the efficiency of the allocation of labour and for the distortions due to taxes, social security, and labour market regulations imposed on the formal sector. It therefore also has major implications for economic policy. This explains why the role of the informal sector has been analyzed extensively during the last two decades.

Two competing stylized views exist in the literature. The traditional staging hypothesis in the theoretical model of Fields (1975) is that formal sector employment is rationed. Those who cannot obtain a formal sector job search from unemployment, or, if they cannot afford this, work in the informal sector. Informal sector workers have secondary jobs and would be better off with a primary job in the formal sector. The informal sector is a buffer between not working and working in the formal sector. In the standard version of this model, the attractiveness of a job is determined by the wage only. This implies wage dualism: in equilibrium, each individual's wage in the informal sector is less than their potential wage in the formal sector.

The other view sees the informal and formal sectors as symmetric and competitive. The two sectors are characterized by different production functions, and worker heterogeneity implies that some are more productive in the formal sector and others in the informal sector. Under the assumption that unrestricted workers choose the sector where they are more productive and can earn the highest wage, this model can be tested using cross-section data on workers' sector choice and wages, see Heckman and Sedlacek (1985). Magnac (1991) applies an extension of this model that also accounts for the state of not working to married women in urban Columbia. He does not reject this model and concludes that the Columbian labor market is in a 'weakly competitive equilibrium.'

Other empirical evidence on sector choice and wage differentials between the formal and the informal sector is mixed. For example, Strassmann (1987) found that 71 percent of home workers in Lima would require a considerable financial incentive to move to the formal sector (see also Thomas, 1992). Pradhan and Van Soest (1995) estimated reduced form models for urban Bolivia, explaining the choice between three states: formal sector, informal sector, and not working. Comparing models in which the three states are ordered and not ordered, they found that the ordered model performs better for men but not for women. Using the same data and a structural labour supply model, Pradhan and van Soest (1997) found that wage differentials between formal and informal sector tend to be negative rather than positive, and that non-monetary job characteristics (job stability, social security, health care access, etc.) are needed to explain why so many people prefer formal sector jobs. Other studies on wage differentials for various countries

give mixed results, see the overview in Pradhan and van Soest (1995). All these studies are based on cross-section data. 
One of the few studies on this issue using panel data is Maloney (1999). He studies wage differentials and transition patterns of workers with at most high school education, using panel data on urban Mexico (covering 1991-1992). He concludes that "much of the informal sector is a desirable destination and the distinct modalities of work are relatively well integrated." His findings largely seem to support the competitive view, although he carefully points out the caveats of the reduced form models that he uses, hampering an unambiguous conclusion. The other panel data study we know off is Gong, van Soest and Villagomez (2000), who use the same data source as Maloney. They use dynamic discrete choice models with random effects to investigate labor market mobility between the three labour market states informal sector work, formal sector work, and not working. They emphasize the role of education level for labor market mobility. They do not explicitly incorporate the effect of wages or wage differentials on the sector choice. The strong education effects they find thus could reflect wage effects.

In the current study, we construct one panel data model for sector choice and mobility as well as wages, in which the effects of wage rates on sector choice are explicitly incorporated. For men, we consider the choice between formal and informal sector; for women, we also consider nonemployment. ${ }^{1}$ The model consists of a dynamic binomial (men) or multinomial (women) logit model for panel data with random effects explaining the labor market state of each individual in each time period, together with two dynamic wage equations for potential wage rates in each sector. We estimate it using five quarterly panel waves drawn from Mexico's Urban Employment Survey, the same survey that was used by Gong et al. (2000) and Maloney (1999).

The first aim of our study is to analyze wage formation and wage differentials controlling for selectivity bias due to correlated unobserved heterogeneity affecting wages and sector choice. This should lead to a better insight in the underlying differences in wage formation in the two sectors than the uncorrected wage differentials used by Maloney (1999). Second, allowing both sectors' wages to directly affect the sector choice, we analyze the importance of wages for sector choice and mobility. With the help of the estimates and additional model simulations, we study the mobility patterns between the two sectors and, for women, nonemployment. We analyze how these patterns vary across groups with different characteristics and family resources, and distinguish between unobserved heterogeneity and true state dependence. The main novelty of our paper is that we address wages and sector choice simultaneously in a dynamic panel data model. Maloney (1999) uses separate models for wages and sector choice, and does not control for unobserved heterogeneity in the sector choice model. Gong et al. (2000) consider a model for sector choice only.

Mexico is a particularly relevant country for studying the role of the informal sector. A typical feature is the low unemployment rate. Since the 1980 's, the official urban unemployment rate decreased continuously, to 2.6 percent in 1991. It remained below

\footnotetext{
${ }^{1}$ The number of nonemployed men is too small to get useful estimates of the structural model we consider.
} 
4 percent until 1994 (see Fleck and Sorrentino, 1994), while Mexico's labor force grew at an annual rate of about 2.9 percent. An explanation for the low unemployment rate is the existence of the informal sector where many individuals have some marginal job.

While formal sector employment is subject to regulation, social premiums and taxation, with wages paid on a regular basis and explicit contracts between employers and employees, the informal sector consists of very small firms that are not subject to institutional regulations. Two explanations for the existence of a large informal sector in Mexico can be given. First, Mexico's formal sector labor market regulations are quite extensive. Mexican Federal Labor Law governs virtually every aspect of labor relations, such as minimum wages, limits on working hours, overtime pay, profit sharing, etc. Many regulations were especially designed to protect the individual employees' employment security (see Hollon, 1996, and Zelek and de la Vega, 1992), such as rules for termination of employment (including severance payments). In addition, the government places health and safety requirements on formal sector firms. All this would make hiring prohibitively costly for small firms. Many small firms thus avoid the requirements; they do not officially register and thus are in the informal sector. Second, Mexico has no system of unemployment compensation, so that individuals without (formal) work are often forced into "marginal activities," such as street vending, etc. Only those who can afford it do not undertake such activities and search from unemployment (See Fleck and Sorrentino, 1994).

Our main findings are as follows. The wage is the main deterministic factor for the individual's sector choice. Wage differentials between the formal and informal sector are typically small for the lower educated, but increase strongly with education level. This also explain why the probability of formal sector employment strongly increases with education level. For men, the probability of working in the informal sector decreases with the income of other family members, while for women, other family income increases the probability of not working. This confirms that only those do not work who can afford to do so, in line with the staging hypothesis.

The remainder of the paper is organized as follows. Section 2 describes the data: five quarterly waves drawn from the Mexico Urban Employment Survey, from the first quarter of 1992 to the first quarter of 1993. We describe the wage distributions in the two sectors, the size of the three sectors in each wave, and the transition rates. The econometric model is discussed in Section 3. The results are presented in Section 4. We discuss wage differentials and transition probabilities for groups of men and women with various background characteristics. Conclusions are drawn in section 5 .

\section{Data}

The data used in the analysis were drawn from Mexico's Urban Employment Survey (Encuesta Nacional de Empleo Urbano), conducted by Instituto Nacional de Estadistica, Geografia e Informatica (INEGI, i.e. Mexican Statistical Institute). This is a rotating 
panel drawn in 32 Mexican cities, and it is the only quarterly household panel survey in Mexico. For our analysis, we use the data for five Mexican cities: Mexico City, Guadalajara, Monterrey, Tijuana, and Ciudad-Juarez. These five cities cover 60 percent of urban employment in Mexico. In the border towns Tijuana and Ciudad-Juarez the inbond industries concentrate. Mexico City, Guadalajara and Monterrey represent about a quarter of the entire population of Mexico, and half of the population of cities with more than 100,000 inhabitants. Guadalajara is the city with the largest share of informal workers (see Villagomez, 1998). Our panel covers a period of economic growth: the first quarter of 1992 until the first quarter of $1993 .^{2}$.

The survey provides detailed information on the economic activities of all the household members older than twelve, such as employment status, employment conditions, working hours, labor income, characteristics of the workplace, etc., but no information on non-labor income. The same data source has been used in several earlier studies. Fleck \& Sorrentino (1994) used it to analyze unemployment in urban Mexico; Villagomez $(1996,1998)$, Calderón-Madrid (1999), and Maloney (1999) used it to study labour market segmentation and mobility.

The sample consists of about 2500 households in each wave. We created separate unbalanced panels of men and Women, selecting only those individuals who are present in at least two consecutive quarters. Moreover, we only selected men and women who are either the head of the household or the spouse of the head of the household, who are younger than 65 years of age, and who are not full-time students. These selections lead to samples of 1691 males and 1907 females. We had to remove 269 males and 627 females because information on other family members' income was missing. Finally, we removed 18 male and 82 female unpaid family workers, who could not be classified in the formal or the informal sector. The sample of women we will use in the estimations thus consists of 1198 observations. Among the male respondents, 94 individuals were not employed during at least two consecutive waves. This number is so small that it would not be possible to estimate the model with non-working as a separate labor market state. These 94 men are therefore excluded from the sample used in estimation, which consists of 1310 men. About $64 \%$ of the respondents are present in all the five waves, and about $12 \%$ in only two waves. In Table A1 and Table A2 of the appendix, we present definitions and sample statistics of the independent variables used in the analysis. Here we focus on the dependent variables.

In the introductory section, we have not precisely defined the distinction between formal and informal sector jobs. Many definitions are used in the existing literature. In this paper, we will use a definition based upon firm size, following Maloney (1999). ${ }^{3}$

\footnotetext{
${ }^{2}$ We also estimated our models for the five panel waves drawn in 1994-1995, but found very similar results as for the 1992-1993 waves. We therefore present and discuss the panel of 1992-1993 only.

${ }^{3}$ The alternative (job type) definition is based on a survey question which distinguishes various sorts of jobs (Magnac, 1991, Pradhan and van Soest, 1995, 1997). Piece-workers and those who work for their own account or manage a firm without employees are categorized as informal. Those who work for a fixed wage, cooperative workers, employers (with at least one employee) and independent
} 
According to this definition, an individual works in the informal sector if he or she is an employer or employee in a firm with fewer than six workers, and is neither a professional nor an unpaid family worker. ${ }^{4}$ Professionals (lawyers, doctors, etc.; about $5 \%$ of men and $0.5 \%$ of women) are categorized as formal sector workers, together with all those in enterprises of more than five workers. Unpaid family workers can not be categorized as workers or non-workers, and were therefore deleted from the sample.

Because of the small numbers of people classifying themselves as unemployed, we do not distinguish unemployment as a separate labor market state, but merge the unemployed with other non-workers. Table 1 shows how the sample percentages of nonworkers and formal and informal sector workers evolve over time. For men, the formal and informal sector workers represent about $58 \%$ and $35 \%$ of the labor force, respectively. The majority of women does not participate in the labor market. About $18 \%$ of women worked in the formal sector, and about $13 \%$ in the informal sector.

Table 1. Formal sector, informal sector, and nonemployment in \% of total labor force

\begin{tabular}{l|l|l|l|l|l}
\hline \hline Quarter & 92.1 & 92.2 & 92.3 & 92.4 & 93.1 \\
\hline Males & & & & & \\
Formal & 57.9 & 56.4 & 58.8 & 58.6 & 57.7 \\
Informal & 35.8 & 35.4 & 34.6 & 34.1 & 34.2 \\
Nonempl. & 6.4 & 8.2 & 6.6 & 7.3 & 8.1 \\
\hline Females & & & & & \\
Formal & 17.6 & 17.6 & 17.8 & 18.4 & 17.8 \\
Informal & 13.6 & 12.5 & 12.1 & 12.5 & 12.6 \\
Nonempl. & 68.8 & 70.0 & 70.1 & 69.0 & 69.6 \\
\hline
\end{tabular}

Wages are observed for about $88.2 \%$ and $90.5 \%$ of working men and women, respectively. Figures 1 and 2 compare means and standard deviations of log real wages in the two sectors in each wave. ${ }^{5}$ We do this separately for those of the higher (at least intermediate) and lower (less than intermediate) education levels (see Table A1 in the appendix). For men and women with higher education levels, the Average log wages are always much larger in the formal sector than in the informal sector. The sample standard deviations of the log wages in the two sectors are similar. The higher average wage in the formal sector may have two explanations: either the formal sector has the

professionals, are categorized as formal. A third definition which is less common in the international literature on countries other than Mexico, is based upon whether social security premiums are paid (see Calderón-Madrid, 1999, and Martin, 1999). We compared the classifications according to these three definitions, and found that the transition patterns are similar (see Gong et al., 2000).

${ }^{4}$ This is similar to the Mexican government's definition, which classifies firms with fewer than six workers as informal.

${ }^{5}$ Nominal wages are computed as monthly income divided by actual working hours; real wages are obtained using the IMF CPI as the deflator (Source: Data Stream). Qualitatively similar results are obtained if monthly earnings are used instead of hourly wage rates. 
more productive jobs, and each individual would be paid more in the formal than in the informal sector, or the high productivity workers select themselves into the formal sector. Controlling for observed and unobserved characteristics and selection effects in the econometric model will show to which extent these explanations are relevant.

For individuals with lower education levels a very different picture emerges. The differences in the means are small and for men, the average "raw" wage differential between formal and informal sector is negative in all time periods. The standard deviation in the formal sector is smaller than in the informal sector, particularly for women. This suggests that the informal sector is more heterogeneous than the formal sector, a result also found by Pradhan and van Soest (1995). The informal sector comprises marginal activities with very low earnings such as street vending, but also highly productive self-employment.

In Table 2, we present some sample statistics on changes of individual log real wages between consecutive quarters. Along with means we also report medians, which are more robust to outliers. We do this separately for those who stay in the same sector and for those who change sector. The general picture is that average wage changes typically do not significantly differ from zero. Exceptions are the median for men who stay in the formal sector, which is significantly lower than zero, and the mean and median for men who move from the formal to the informal sector, which are significantly positive. Some nonparametric regressions of wage differentials against age are presented in Figures 3 and 4. These figures show no evidence of wage differentials for almost any age group.

The sample standard deviations of the real wage changes are huge. This is not only due to a few outliers, since the interquartile ranges are very large as well. Apparently, many people report very different wages in consecutive waves, even if they stay in the same sector. ${ }^{6}$ For example, for about $25 \%$ of all men who stay in the formal sector in two consecutive quarters, the wage rate in the second wave is more than $24 \%$ lower than the wage in the first wave. Although it seems conceivable that wage mobility is larger in Mexico than in industrial countries in North-America or Europe, we think these large numbers must at least partly be due to measurement errors in reported wages. This suggests that the measurement error should somehow be taken into account in the model. We will come back to this in the next section.

\footnotetext{
${ }^{6}$ This result remains unchanged if monthly earnings are considered instead of hourly wage rates.
} 
Table 2. Real wage changes by sector

\begin{tabular}{l|l|l|l|l}
\hline \hline$t=1$ & \multicolumn{2}{|c}{ Formal sector } & \multicolumn{2}{c}{ Informal sector } \\
\hline$t=2$ & formal & informal & formal & informal \\
\hline Men & & & & \\
Mean & 0.009 & 0.097 & 0.039 & 0.008 \\
Std.err.of Mean & 0.014 & 0.045 & 0.049 & 0.022 \\
$25^{\text {th } \text { Percentile }}$ & -0.277 & -0.255 & -0.404 & -0.409 \\
Median & -0.019 & 0.108 & 0.038 & -0.025 \\
Std.err.of Median & 0.005 & 0.038 & 0.039 & 0.016 \\
$75^{\text {th }}$ Percentile & 0.301 & 0.420 & 0.379 & 0.374 \\
Obs. & 1958 & 197 & 195 & 958 \\
\hline Women & & & & \\
Mean & -0.054 & -0.178 & 0.127 & 0.013 \\
Std.err.of Mean & 0.041 & 0.165 & 0.149 & 0.050 \\
$25^{\text {th }}$ Percentile & -0.342 & -0.516 & -0.105 & -0.432 \\
Median & -0.019 & -0.166 & 0.049 & -0.019 \\
Std.err.of Median & 0.013 & 0.176 & 0.082 & 0.020 \\
$75^{\text {th }}$ Percentile & 0.270 & 0.331 & 0.430 & 0.492 \\
Obs. & 574 & 31 & 32 & 319 \\
\hline
\end{tabular}

In Table 3, the sample probabilities of transitions among the three labor market states are presented. Female nonworkers have a larger probability to find an informal job than to find a formal job. As shown in the table, the probabilities of remaining in the formal sector are larger than those of remaining in the informal sector, suggesting that exit rates from the formal sector are lower than exit rates from the informal sector. This does not necessarily mean that jobs in the formal sector are more stable than jobs in the informal sector; It could be that job separations for formal and informal sector jobs are equally likely, and that the difference in sector exit rates is due to the fact that the probability that someone who leaves a job in the formal sector finds another formal sector job, is larger than the probability that someone who leaves an informal sector job, goes to another informal sector job. The mere difference in size between the sectors might be a plausible explanation for this, particularly for men. Since the data do not provide information on whether people change jobs or not, we can only look at sector mobility and cannot compare job mobility in the two sectors. 


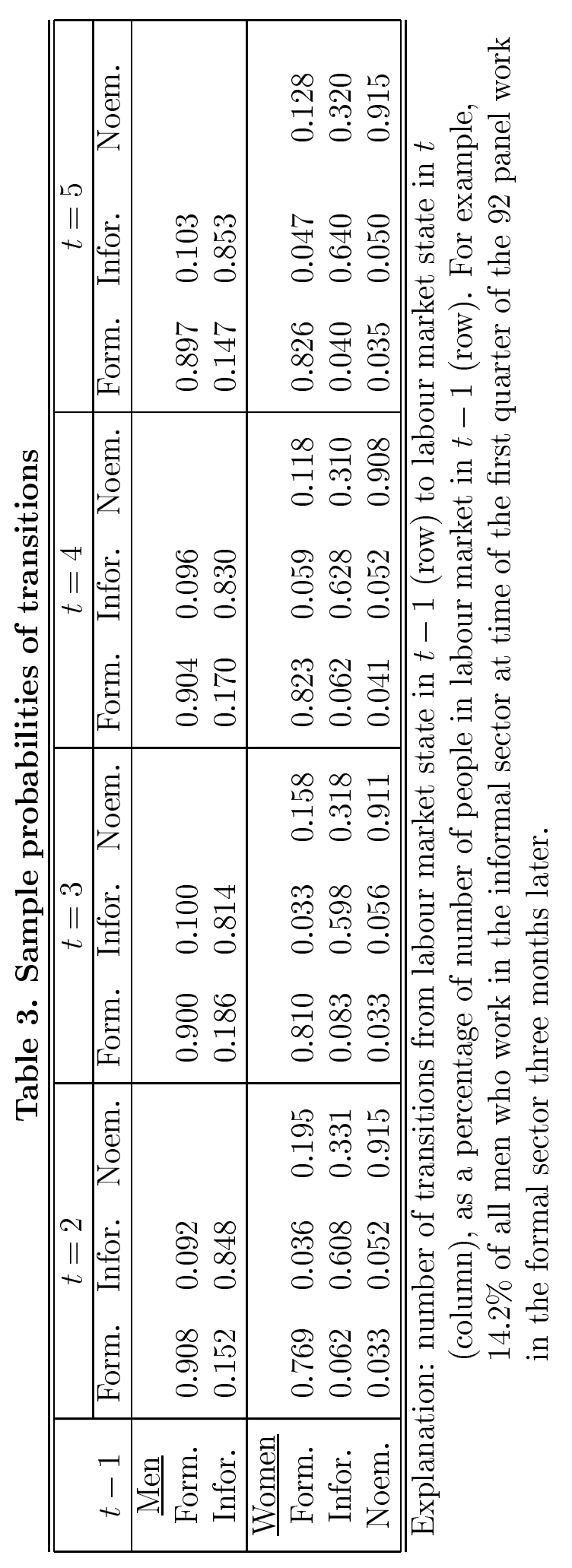




\section{The model}

To explain the wage differentials between the two sectors and the labor market state of each individual in each quarter, we introduce a joint model for labor market state choices and wages. We use a dynamic (binomial or multinomial) logit panel data model with random effects for the choices, and two linear dynamic random effect wage equations for the wages in the two sectors. Wages are included in the choice equations. A respondent's wage rate in a given sector in a given quarter is only observed if the respondent works in that sector during that period. This implies that the choice model cannot be estimated without the wage equations. The model we use is a generalization of the first-order Markov model of Heckman (1981a). It distinguishes between structural state dependence and unobserved heterogeneity by including lagged state dummies as explanatory variables and (random) individual effects to control for unobserved individual characteristics. The individual effects are assumed to be independent of the observed characteristics (and therefore called random effects) and are assumed to follow a normal distribution. The initial condition problem due to applying this model to a short panel is treated as in Heckman (1981b).

The model includes two parts, the choice model and two wage equations. The wage equations are specified as follows.

$$
\ln w_{t j}=M_{t}^{\prime} \nu_{j}+D_{t-1}^{\prime} \tau_{j}+\lambda_{j}+\zeta_{t j}, \quad j=1,2 .
$$

Here $j=1$ denotes the formal sector, and $j=2$ is the informal sector. For notational convenience, we suppress the subscript for individuals. $M_{t}$ is a vector of individual characteristics (including a constant term, educational dummies, regional dummies, time dummies and age). $D_{t-1}$ is a (vector of) dummy variable(s) indicating the lagged labor market state. For men, it is just one dummy for the formal sector (taking the informal sector as the reference state). For women, it consists of two dummies for the formal and the informal sector, with not working as the reference state. The random individual effects in the two wage equations are denoted by $\lambda_{j}$. We assume that they are i.i.d. normal with mean zero and independent of the exogenous variables. The $\zeta_{t j}$ are idiosyncratic error terms, assumed to be i.i.d. normal and independent of other error terms, individual effects, and exogenous variables. $\nu_{j}$ and $\tau_{j}$ are parameters to be estimated. We do not impose any constraints relating the parameters of the wage equations in the formal and informal sector, so that wage formation is allowed to be completely sector specific.

The error terms $\zeta_{t j}$ reflect measurement error and genuine unsystematic wage variation over time in a given sector for a given individual. The two cannot be separately identified, but the descriptive statistics in Table 2 suggest that measurement error plays a dominating role. In the sector choice part of the model, wages will play a role, and consistent estimation requires including a wage variable cleaned for measurement error. To achieve this, we will use "predicted" $\log$ wages $\ln w_{t j}^{p}$ given by

$$
\ln w_{t j}^{p}=M_{t}^{\prime} \nu_{j}+D_{t-1}^{\prime} \tau_{j}+\lambda_{j}=\ln w_{t j}-\zeta_{t j}, \quad j=1,2 .
$$


We put "predicted" in quotes here, since this wage variable includes the random effect $\left(\lambda_{j}\right)$, which is not estimated, but is assumed to be known by the individuals when they choose their labour market state. On the other hand, the respondents choose the state without taking account of $\zeta_{t j}$, either since this is measurement error or because this is not known to them when they make their choice. We can now define the choice part of the model. An individual can be in any of $J$ possible labor market states at time $t(J=2$ for men and $J=3$ for women): working in the formal sector $(j=1)$, working in the informal sector $(j=2)$, and not working $(j=3)$. For notational convenience, we define $\ln w_{t 3}^{p}=0$. The "utility" of state $j(j=1, \ldots, J)$ in time period $t>1$ is specified as

$$
V(j, t)=X_{t}^{\prime} \beta_{j}+D_{t-1}^{\prime} \gamma_{j}+\alpha_{j}+\rho \ln w_{t j}^{p}+\epsilon_{j t} .
$$

The reason for the quotes on "utility" is that demand side restrictions may play a role. Thus $V$ may reflect more than supply factors or preferences. A low value of $V(1, t)$, for example, may mean that no formal job is available at time $t$, even though the respondent could have a strong preference for such a job.

$X_{t}$ is a vector of explanatory variables, including age, regional dummies, family composition, time dummies, etc. Educational dummies are not included in $X_{t}$, but they enter through $M_{t}$ in the wage equations. Excluding educational dummies from (3) is necessary to identify the model. The vectors $\beta_{j}$ and $\gamma_{j}$ are parameters to be estimated. The $\alpha_{j}$ are random individual effects reflecting time invariant unobserved heterogeneity. We assume that the $\alpha_{j}$ are i.i.d. normal with mean zero, and are independent of $X_{t}$ and $M_{t}$. By means of normalization, $\beta_{1}, \gamma_{1}$, and $\alpha_{1}$ are set to 0 .

How attractive the various labor market states are, also depends on potential wages. We include the "predicted" wage rates as explanatory variables, with coefficient $\rho$. The assumption that the effect of wages on utility is the same in the formal and informal sector implies that the utility difference between these two sectors depends on the log wage differential. The $\epsilon_{j t}$ are i.i.d. error terms, assumed to be independent of the $X_{t}$, $\alpha_{j}$, and other error terms in the model and following a Type I generalized extreme value (GEV I) distribution.

The random effects are assumed to be multivariate normal. We allow for non-zero correlation between random effects of different states, but not between random effects in the wage and state choice equations. The latter implies that correlation between random effects in choice and wage equations thus only enters through the structural part $\rho \ln w_{t j}^{p}$ in the choice equations. ${ }^{7}$ Correlations between the idiosyncratic errors $\zeta$ and $\epsilon$ are also ruled out.

The assumptions imply that, given characteristics $X_{t}$ and $M_{t}$, random effects $\boldsymbol{\alpha}=$ $\left(\alpha_{2}, \ldots, \alpha_{J}\right)^{\prime}$ and $\boldsymbol{\lambda}=\left(\lambda_{1}, \lambda_{2}\right)^{\prime}$, and the lagged state dummies, the conditional likelihood contribution for individual $i$ in state $j$ at time $t>1, L_{t}\left(j \mid X_{t}, M_{t}, D_{t-1}, \boldsymbol{\alpha}^{\prime}, \boldsymbol{\lambda}^{\prime}\right)$, is given

\footnotetext{
${ }^{7}$ We estimated the model allowing for correlation between $\alpha_{j}$ and $\lambda_{j}$ but this did not lead to significant improvement.
} 
by

$$
\left\{\frac{\exp \left(X_{t}^{\prime} \beta_{j}+D_{t-1}^{\prime} \gamma_{j}+\alpha_{j}+\rho \ln w_{j t}^{p}\right)}{\sum_{s=1}^{J} \exp \left(X_{t}^{\prime} \beta_{s}+D_{t-1}^{\prime} \gamma_{s}+\alpha_{s}+\rho \ln w_{s t}^{p}\right)}\right\} f_{j}\left(\ln w_{t j}-\ln w_{t j}^{p}\right),
$$

if the wage in sector $j$ is observed. If no wage is observed (non-employed females or cases with missing wages) the conditional likelihood contribution is

$$
\frac{\left\{\exp \left(X_{t}^{\prime} \beta_{j}+D_{t-1}^{\prime} \gamma_{j}+\alpha_{j}+\rho \ln w_{j t}^{p}\right)\right.}{\sum_{s=1}^{J} \exp \left(X_{t}^{\prime} \beta_{s}+D_{t-1}^{\prime} \gamma_{s}+\alpha_{s}+\rho \ln w_{s t}^{p}\right)},
$$

Due to the presence of the lagged dependent variables in $D_{t-1}$, an initial conditions problem arises. This is solved in the same way as in Heckman (1981b): for $t=1$, a static multinomial logit model replaces equation(3), with different parameters and not including $D_{t-1}$. The initial conditions problem in the wage equations at $t=1$ is treated in the same way. The static equations can be seen as approximations to some reduced form, eliminating the lagged state dummies. Heckman's Monte Carlo results for the dynamic random effects probit model suggest that this procedure leads to a small asymptotic bias only.

Given the random effects, the conditional likelihood contribution of individual $i$ with observed states $j_{1}, \ldots, j_{T}$ would be given by

$$
L(\boldsymbol{\alpha}, \boldsymbol{\lambda})=\Pi_{t=1}^{T} L_{t}\left(j_{t} \mid X_{t}, M_{t}, D_{t-1}, \boldsymbol{\alpha}^{\prime}, \boldsymbol{\lambda}^{\prime}\right)
$$

Since the random effects are not observed, the likelihood contribution will be given by the expected value of (6):

$$
L=\underbrace{\int_{-\infty}^{\infty} \cdots \int_{-\infty}^{\infty}}_{2 J-2} L(\boldsymbol{\alpha}, \boldsymbol{\lambda}) \phi_{J-1}(\boldsymbol{\alpha}) \phi_{2}(\boldsymbol{\lambda}) \mathrm{d} \boldsymbol{\alpha} \mathrm{d} \boldsymbol{\lambda}
$$

where the $\phi_{K}$ are the densities of $\boldsymbol{\alpha}$ and $\boldsymbol{\lambda}$. Computation of the likelihood contribution in (7) involves $2 J-2$ dimensional integration. This can be done in several ways. We will use (Smooth) Simulated Maximum Likelihood. Given that (7) is the expected value of (6), it is approximated by a simulated mean. For each individual, $R$ values of $\boldsymbol{\alpha}$ and $\boldsymbol{\lambda}$ are drawn and the average of the $R$ likelihood values conditional on these drawn values are computed. The integral in (7) is thus replaced by

$$
L_{i}^{R}=\frac{1}{R} \sum_{q=1}^{R} L_{i}\left(\boldsymbol{\alpha}_{i}^{q}, \boldsymbol{\lambda}_{i}^{q}\right)
$$

The resulting estimator is consistent if $R$ tends to infinity with the number of observations $(n)$. If $n^{1 / 2} / R \rightarrow 0$ and with independent draws across observations, the method

\footnotetext{
${ }^{8}$ Chay and Hyslop (2000) compare various ways of dealing with the initial conditions and find that the Heckman procedure works better than other procedures.
} 
is asymptotically equivalent to maximum likelihood, see Hajivassiliou and Ruud (1994), for example. In our empirical setting, we used $R=30$. To check the sensitivity of the results for the choice of $R$, we also estimated the model for $R=20$, and found little change in the results when we increased $R$ from 20 to 30 .

\section{Results}

We only report the estimates of the dynamic equations. The estimates of the static reduced form equations are available on request.

\section{Wages and wage differentials}

Table 4 presents the estimates of dynamic wage equations (1) for men and women. Several findings are common for men and women. First, age has a significant effect on the formal sector wage, but not on the informal sector wage. The formal sector wage first increases and then decreases with age. Second, we find positive returns to education in both sectors, which are higher in the formal sector than in the informal sector. For example, in the formal sector, a man with high education level can earn about $145 \%$ more than a man with the lowest education level (ceteris paribus). In the informal sector, the difference is only 37\%. An explanation might be that in the larger formal sector firms, it is difficult for the employers to observe workers' productivity directly, and experience and education level are used as signals. In the small informal sector firms on the other hand, employers have direct contacts with the employees, and age and education will have less signalling ingredients. ${ }^{9}$

In the two border cities Tijuana and Ciudad-Juarez, the wages in both sectors are higher than in Mexico City. This reflects the fact that many in bond industries ${ }^{10}$ are located in here. These are usually owned by multinationals or are joint-ventures with multinationals, and typically pay better than other (domestic) firms.

There is only weak evidence that the lagged labour market state affects current earnings. Only for men in the formal sector, we find an effect which is significant at the two-sided $10 \%$ level), implying that those who were in the formal sector in the previous quarter earn more than newcomers, ceteris paribus. For men as well as women, we find little evidence of random effects in the wage equations: the estimated variances of the random effect terms are very small. On the other hand, the idiosyncratic errors are quite large, in line with the large standard deviations of wage changes in Table 2. The variance of the idiosyncratic part of wages of men is larger in the formal than in the informal sector. This is not in line with the finding of Pradhan and van Soest (1995) that the informal sector is more heterogeneous and has larger wage dispersion. On the

\footnotetext{
${ }^{9}$ Stigler (1962) has already suggested that small firms suffer may more easily recognise and reward ability rather than formal schooling.

${ }^{10}$ so called Maquiladoras, see Martin (1999) for some institutional background information
} 
other hand, the variance of females' formal sector wages is about $14 \%$ less than that of informal sector wages.

Table 4. Wage equations

\begin{tabular}{|c|c|c|c|c|}
\hline \multirow[b]{2}{*}{ Param. } & \multicolumn{2}{|c|}{ Men } & \multicolumn{2}{|c|}{ Women } \\
\hline & form. & Info. & form. & Info. \\
\hline \multicolumn{5}{|l|}{$\nu_{j}:$} \\
\hline Const. & $0.871(3.70)$ & $1.483(5.19)$ & $0.185(0.42)$ & $1.368(2.34)$ \\
\hline Age & $0.037(3.38)$ & $0.008(0.60)$ & $0.052(2.40)$ & $0.013(0.45)$ \\
\hline Age2 & $-0.0005(-3.40)$ & $-0.0001(-0.50)$ & $-0.0005(-1.76)$ & $-0.0002(-0.56)$ \\
\hline Medu & $0.238(6.99)$ & $0.105(4.37)$ & $0.495(6.19)$ & $0.099(1.80)$ \\
\hline Hedu & $0.898(24.5)$ & $0.317(4.37)$ & $0.844(8.03)$ & $0.175(1.69)$ \\
\hline JuaTij & $0.361(9.27)$ & $0.515(9.22)$ & $0.218(2.67)$ & $0.345(3.00)$ \\
\hline Guada & $-0.129(-3.03)$ & $-0.057(-1.04)$ & $0.027(0.23)$ & $-0.083(-0.84)$ \\
\hline Mont. & $0.202(5.58)$ & $0.297(5.17)$ & $0.118(1.68)$ & $0.180(1.78)$ \\
\hline T3 & $-0.042(-0.76)$ & $-0.086(-1.24)$ & $-0.025(-0.24)$ & $0.086(0.61)$ \\
\hline T4 & $0.088(1.57)$ & $-0.062(-0.88)$ & $0.092(0.82)$ & $0.086(0.68)$ \\
\hline T5 & $-0.014(-0.26)$ & $0.005(0.07)$ & $0.085(0.77)$ & $0.230(1.61)$ \\
\hline $\begin{array}{l}\tau_{j}: \\
\text { form }\end{array}$ & & & & \\
\hline $\begin{array}{l}\text { form. }-1 \\
\text { In fo. }-1\end{array}$ & $0.124(1.84)$ & $0.018(0.27)$ & $\begin{array}{l}0.048(0.51) \\
-0.069(0.35)\end{array}$ & $\begin{array}{l}-0.025(-0.10) \\
-0.066(-0.73)\end{array}$ \\
\hline$\Sigma_{\lambda}:$ & \multirow{2}{*}{\multicolumn{2}{|c|}{$0.0001(1.53)$}} & \multirow{2}{*}{\multicolumn{2}{|c|}{$00002(1$ 15) }} \\
\hline$\sigma_{2}^{\hat{2}}$ & & & & \\
\hline$\sigma_{3}^{2}$ & \multicolumn{2}{|c|}{$0.0000(0.35)$} & \multicolumn{2}{|c|}{$0.0000(0.07)$} \\
\hline$\sigma_{23}$ & \multicolumn{2}{|c|}{$-0.0000(-0.03)$} & \multicolumn{2}{|c|}{$-0.0000(-0.13)$} \\
\hline$\Sigma_{\zeta}:$ & \multirow{3}{*}{\multicolumn{2}{|c|}{$\begin{array}{l}0.701(48.07) \\
0.691(29.63)\end{array}$}} & \multirow{3}{*}{\multicolumn{2}{|c|}{$\begin{array}{l}0.632(20.77) \\
0.720(17.63)\end{array}$}} \\
\hline$\sigma_{2}^{2}$ & & & & \\
\hline$\sigma_{3}^{2}$ & & & & \\
\hline
\end{tabular}

Notes:

$t$-values in parentheses

$\sigma_{j}^{2}$ : variances of $\lambda_{j}\left(\zeta_{j}\right), j=2,3 ; \sigma_{23}$ : covariance of $\lambda_{2}$ and $\lambda_{3}$

"Lowedu", "T1", and "Mex. City", are the omitted control group dummies

We estimated the the wage differentials for some individuals with given benchmark characteristics. The results are summarized in Table 5 and Figures 5 and 6 . The latter are based upon individuals who work in Mexico City and who worked in the formal sector in the previous quarter. Most wage differentials between formal and informal sector are positive. ${ }^{11}$ For both men and women, wage differentials increase strongly with education level. Wages of unskilled workers are not significantly different in the two sectors, but wages in the formal sector are significantly higher than in the informal sector for higher

\footnotetext{
${ }^{11}$ Empirical evidence for the US and other OECD countries also shows that large firms tend to pay more than small firms (See, for example, Siebert and Addison (1991), Mellow (1992), etc..), and the survey of Polachek and Siebert (1996).
} 
educated individuals. For example, Table 5 shows that the wage differentials are about $89 \%$ for men and about $96 \%$ for women of age 40 with high education who had a formal sector job in the previous quarter in Mexico City. The wage differentials also vary with age. For men (Figure 5), the differential increases with age until about age 40 and falls after that. The wage differential for women (Figure 6) increases with age over the whole range. As explained by Magnac (1991) and Maloney (1999), these wage differentials alone do not lead to unambiguous conclusions on the nature of formal sector vis a vis informal sector jobs, even though selection effects are now corrected for. The competitive model can still be valid if either the majority of high educated workers (who can earn more in the formal sector) indeed work in the formal sector, or non-wage job characteristics make the informal sector more attractive for many people. Still, the wage differentials for the higher educated individuals suggest that different mechanisms play a role for the higher and lower educated.

Table 5. Wage differentials for some benchmark persons

\begin{tabular}{|lcc|}
\hline \hline Charateristics & Males & Females \\
\hline Mex. City; ex-formal worker; Low-edu. & 0.058 & 0.005 \\
& $(0.101)$ & $(0.259)$ \\
\hline Mex. City; ex-formal worker; Mid-edu. & 0.191 & 0.402 \\
& $(0.097)$ & $(0.259)$ \\
\hline Mex. City; ex-formal worker; High-edu. & 0.638 & 0.675 \\
& $(0.112)$ & $(0.273)$ \\
\hline Mex. City; ex-informal worker; Low edu. & -0.049 & 0.067 \\
& $(0.103)$ & $(0.226)$ \\
\hline J. \& T.; ex-formal worker; Low edu. & -0.097 & -0.067 \\
& $(0.104)$ & $(0.186)$ \\
\hline Mex. City; ex-notemployed; Low edu. & - & -0.122 \\
& & $(0.282)$ \\
\hline \hline
\end{tabular}

Standard errors in parentheses. Age $=40$.

\section{Mobility}

The estimates of the dynamic choice equations in (3) are presented in Table 6 . A positive sign of the parameter $\beta_{j}$ or $\gamma_{j}(j=2,3)$ means that the corresponding variable has a positive impact on the probability to be in state $j$ compared to the probability to be in the reference state (the informal sector for men, non-employment for women). Wage effects are significantly positive for both men and women. For men this means that a higher wage differential between formal and informal sector leads to a larger probability to work in the formal sector, given the other characteristics and the labor market state 
in the previous quarter. For women, it also means that a higher wage in the formal or in the informal sector increases the probability to participate.

The variances of the random effects are substantial and significant. The random effects in the state equations thus play a much larger role than the random effects in the wage equations. They contribute more to explaining the state choice than the idiosyncratic errors (which all have variance $\pi^{2} / 6$ ). Moreover, for women, the two individual heterogeneity terms are positively correlated.

Given the wage rates, men's sector choice is not significantly affected by age. The lack of a clear age effect corresponds to Maloney's finding that the effects of experience on mobility are not clear. He interprets this as evidence against the staging hypothesis, since this hypothesis implies that the more experienced who have queued longer, have a larger probability to work in the formal sector. Somewhat surprisingly, men's sector choice is not affected by their labour market state in the previous quarter. This implies that there is no genuine state dependence. Te fact that men tend to stay in the same sector is explained by observed and unobserved heterogeneity and is not a structural effect. For women, the estimates indicate that being in either of the three states increases the probability of being in that same state in the next quarter. There are no cross-effects: women who are not employed have the same probability to find a formal (informal) sector job as women in the informal (formal) sector with the same characteristics. This is not in line with the notion that people prefer unemployment to informal sector work because it is easier to find a formal sector (primary) job from unemployment than from informal sector employment, which is one of the features of the Fields (1975) model. A plausible explanation for this, however, is that many non-working women are not unemployed but do not participate in the labor market.

The sector choice of men varies across cities and with household composition. For example, living in the two border cities significantly increases the probability of working in the formal sector. This is because workers in the Maquiladoras are classified as formal workers. Higher income of other family member also increases the formal sector probability.

For women, having younger children reduces the probability to work, both in the formal and in the informal sector. This finding is in line with common findings in the literature. In the border cities of Ciudad Juarez and Tijuana, the share of working women in the formal sector is larger than in Mexico City, as expected due to the presence of in-bond (formal sector) industries. Living in one of the border cities increases the probability of non-employment. The in-bond industries pay relatively high wages, but the positive employment effect induced by this sustains for men only. Women either do not like the nature of the jobs (given the wages), or find it harder to get access to them than to formal sector jobs in other cities.

For women, income of other family members ('Othinc') has a significant negative effect on the probability to work in the informal sector. This is in line with the assumption in the Fields (1975) model that individuals with more sources of income can 
afford to search for a formal sector job from unemployment rather than informal sector employment.

Table 6 . Estimates of the dynamic choice equations

\begin{tabular}{|c|c|c|c|}
\hline \multirow[b]{2}{*}{ Param. } & Men & \multicolumn{2}{|c|}{ Women } \\
\hline & form. & form. & Info. \\
\hline \multicolumn{4}{|l|}{$\beta_{j}:$} \\
\hline Const. & $4.195(1.29)$ & $-7.538(-2.96)$ & $-12.721(-4.02)$ \\
\hline Age & $-0.140(-0.87)$ & $-0.022(-0.16)$ & $0.212(1.57)$ \\
\hline Age2 & $0.001(0.47)$ & $-0.001(-0.76)$ & $-0.003(-1.78)$ \\
\hline JuaTij & $1.121(1.78)$ & $-0.950(-1.98)$ & $-1.908(-3.11)$ \\
\hline Guada & $0.044(0.07)$ & $0.095(0.15)$ & $0.554(1.05)$ \\
\hline Mont. & $1.151(1.89)$ & $-0.491(-1.00)$ & $-0.557(-1.06)$ \\
\hline Child & $-0.211(-1.32)$ & $-0.502(-2.90)$ & $-0.372(-2.28)$ \\
\hline Adults & $0.172(1.87)$ & $-0.084(-0.89)$ & $0.042(0.60)$ \\
\hline Othinc & $0.053(1.94)$ & $-0.046(-0.90)$ & $-0.110(-2.89)$ \\
\hline Nmar & $0.080(0.18)$ & $2.910(7.26)$ & $2.483(7.15)$ \\
\hline lwage & $6.885(5.47)$ & $3.998(4.47)$ & \\
\hline T3 & $-0.248(-0.39)$ & $0.295(0.64)$ & $-0.311(-0.52)$ \\
\hline T4 & $-0.874(-1.27)$ & $-0.067(-0.13)$ & $-0.152(-0.27)$ \\
\hline T5 & $0.186(0.30)$ & $-0.160(-0.29)$ & $-0.810(-1.26)$ \\
\hline$\gamma_{j}:$ & & & \\
\hline $\begin{array}{l}\text { form.-1 } \\
\text { In fo. }-1\end{array}$ & $\begin{array}{l}-0.245(-0.35) \\
-\end{array}$ & $\begin{array}{l}1.030(3.32) \\
-0.110(-0.13)\end{array}$ & $\begin{array}{l}-0.419(-0.43) \\
1.505(3.45)\end{array}$ \\
\hline$\Sigma_{\alpha}:$ & & & \\
\hline$\sigma_{2}^{2}$ & $21.121(5.49)$ & & $255(3.90)$ \\
\hline$\sigma_{3}^{2}$ & & & $04(4.38)$ \\
\hline$\sigma_{23}$ & & & $87(4.82)$ \\
\hline Lik. & -8892.0 & & 4396.7 \\
\hline
\end{tabular}

Notes:

1. $t$-values in parentheses

2. Reference state: not-employment

3. $\sigma_{j}^{2}$ : variance of $\alpha_{j}, j=2,3 ; \sigma_{23}$ : covariance of $\alpha_{2}$ and $\alpha_{3}$

4. "Lowedu", "T2", "Mex. City", and "noem.-1"

("infor. -1 "), are the omitted control group dummies

To understand the implications of the estimates for the mobility patterns, we look at simulated transition probabilities. Maloney (1999) explains that the patterns of worker transitions may offer some indication on the validity of the dualistic view. He suggests that if the staging hypothesis were true, one would see very low rates of formal sector turnover, a largely unidirectional flow of workers from informal sector to the formal sector, and the probability of entry into the formal (salaried) work increasing with experience.

The simulations are conducted for the first two quarters, with individual characteristics fixed and the unobserved heterogeneity terms (random effects) either drawn from 
their estimated distributions (Tables 7 and 9) or fixed to the value zero (Tables 8 and 10). In Tables 7 and 9, the marginal probabilities (for given characteristics, but not for given lagged labor market state) are the averages over the draws of the random effects, the conditional probabilities - given characteristics as well as the lagged labor market state - are computed as the ratio of joint and marginal probabilities, both averaged over the random effects. The probabilities are calculated for men and women with high and low education level, with other observed characteristics set to their benchmark values: married with one young child, 40 years old (in the first quarter), etc.. The (predicted) wages are thus fully determined by these observed characteristics and unobserved heterogeneity.

Standard errors of the probabilities are estimated by repeating the simulations for a large number of draws (100 draws in our case) from the estimated asymptotic distribution of the parameter estimates. In Tables 8 and 10, individuals with the same observed charateristics are considered, but the random effects are all set to zero. Differences between Tables 7 and 8 and between Tables 9 and 10 thus say something about the importance of the random effects.

Table 7 shows that $79 \%$ of the group of higher educated men with benchmark characteristics work in the formal sector in the first quarter, due to the large wage differential. In the next quarter, this percentage is still somewhat higher, due to the low probability to move to the informal sector. On the other hand, of the lower educated benchmark men only $62 \%$ work in the formal sector in the first quarter, and this percentage is even lower in the second quarter. The conditional probabilities reveal that, on average (over the random effects), about $94 \%$ of the high educated benchmark men who are in the formal sector, stay in the formal sector in the next quarter, while only $77 \%$ of the high educated men in the informal sector remain in that sector. Of the low educated men in the formal and informal sector, $85 \%$ and $90 \%$ stay in the same sector, respectively.

Comparing Table 7 with Table 8 shows that the main reason why we find that people tend to stay in the same sector, is unobserved heterogeneity. For someone with given (average) unobserved characteristics, the probability of being in the formal sector in the second quarter hardly depends on the labor market state in the first quarter. This is in line with the finding that the lagged labor market state is insignificant, both in the state equations and in the wage equations. The high educated benchmark man with average unobserved characteristics always has a very high probability of being in the formal sector. For the low educated man, the wage differential is smaller, leading to a larger informal sector probability. This probability is about $11 \%$-points higher if the man was already in the informal sector in the previous quarter than if he was not, but this difference is not statistically significant. Thus, for higher educated men, the formal sector turnover is very low $(1.2 \%)$ and there is a unidirectional flow of informal workers to the formal sector. For lower educated men, this is not so: their sector mobility in both directions is substantial.

For women, the non-workers are also included. Table 9 shows that about $56 \%$ of 
the benchmark group of high educated women are employed during the first quarter, and most of them are in the formal sector. About $79 \%$ of the latter stay in the formal sector during the next quarter. On the other hand, only $31 \%$ of the high educated benchmark women in the informal sector stay in the informal sector. Instead, many of them stop working. The transition rates from non-employment to employment are low, particularly into the informal sector. Only $25 \%$ of the low educated benchmark women are employed, and about $60 \%$ of them are in the formal sector. There are many transitions into non-employment from both sectors, and few transitions between sectors.

In Table 10, women with zero value of the random effects are considered. There are substantial differences with Table 9, showing that unobserved heterogeneity plays an important role for women also. Other than for men, the effect of the lagged state remains substantial, showing that for women, there is an important structural effect reflecting genuine state dependence. For example, the probability that the high educated benchmark woman is in the formal sector, is much larger if she has been in the formal sector the previous quarter than if she has been in the informal sector (49\% versus $14 \%$ ). This corresponds to the finding that the estimates of the coefficients on the lagged state dummies are significant. The probability to stay in the same sector for higher educated females is much higher in the formal than in the informal sector, confirming the sector asymmetry for the high educated. Many female workers, however, stop working, and this makes it hard to get insight in the formal informal sector mobility.

Table 7. Simulated Transition Probabilities (Males)

\begin{tabular}{|l||c|c||c|c|}
\hline \hline \multicolumn{1}{|c||}{$j_{t}$} & \multicolumn{2}{c||}{$\operatorname{Prob}\left(j_{t}\right)$} & \multicolumn{2}{c|}{$\operatorname{Prob}\left(j_{2} \mid j_{1}\right)$} \\
\cline { 2 - 5 } & $t=1$ & $t=2$ & Formal & Informal \\
\hline High education & & & & \\
Formal & 0.785 & 0.793 & 0.943 & 0.057 \\
Informal & $(0.068)$ & $(0.028)$ & $(0.026)$ & $(0.026)$ \\
& 0.215 & 0.207 & 0.233 & 0.767 \\
Low education & $(0.068)$ & $(0.028)$ & $(0.092)$ & $(0.092)$ \\
Formal & & & & \\
\multirow{4}{*}{ Informal } & 0.617 & 0.565 & 0.851 & 0.149 \\
& $(0.064)$ & $(0.028)$ & $(0.045)$ & $(0.045)$ \\
& 0.383 & 0.435 & 0.104 & 0.896 \\
& $(0.064)$ & $(0.028)$ & $(0.046)$ & $(0.046)$ \\
\hline \hline
\end{tabular}

Standard errors in parentheses. 
Table 8. Simulated Transition Probabilities (Males, random effects fixed)

\begin{tabular}{|l||c|c||c|c|}
\hline \hline \multicolumn{1}{|c||}{$j_{t}$} & \multicolumn{2}{c||}{$\operatorname{Prob}\left(j_{t}\right)$} & \multicolumn{2}{c|}{$\operatorname{Prob}\left(j_{2} \mid j_{1}\right)$} \\
\cline { 2 - 5 } & $t=1$ & $t=2$ & Formal & Informal \\
\hline High education & & & & \\
Formal & 0.969 & 0.988 & 0.988 & 0.012 \\
Informal & $(0.076)$ & $(0.008)$ & $(0.007)$ & $(0.007)$ \\
& 0.031 & 0.012 & 0.979 & 0.021 \\
Low education & $(0.076)$ & $(0.008)$ & $(0.015)$ & $(0.015)$ \\
Formal & & & & \\
Informal & 0.764 & 0.635 & 0.664 & 0.336 \\
& $(0.158)$ & $(0.092)$ & $(0.086)$ & $(0.086)$ \\
& 0.236 & 0.365 & 0.548 & 0.452 \\
& $(0.158)$ & $(0.092)$ & $(0.097)$ & $(0.097)$ \\
\hline \hline
\end{tabular}

Standard errors in parentheses.

Table 9. Simulated Transition Probabilities (Females)

\begin{tabular}{|c|c|c|c|c|c|}
\hline \multirow[b]{2}{*}{$j_{t}$} & \multicolumn{2}{|c|}{$\operatorname{Prob}\left(j_{t}\right)$} & \multicolumn{2}{|r|}{$\operatorname{Prob}\left(j_{2}\right.$} & $\left.j_{1}\right)$ \\
\hline & $t=1$ & $t=2$ & Formal & Informal & Not employed \\
\hline \multicolumn{6}{|l|}{ High education } \\
\hline \multirow[t]{2}{*}{ Formal } & 0.508 & 0.438 & 0.790 & 0.019 & 0.191 \\
\hline & $(0.071)$ & $(0.051)$ & $(0.034)$ & $(0.015)$ & $(0.039)$ \\
\hline \multirow[t]{2}{*}{ Informal } & 0.048 & 0.039 & 0.111 & 0.307 & 0.583 \\
\hline & $(0.032)$ & $(0.017)$ & $(0.066)$ & $(0.011)$ & $(0.060)$ \\
\hline \multirow[t]{2}{*}{ Not-employed } & 0.444 & 0.523 & 0.070 & 0.033 & 0.897 \\
\hline & $(0.070)$ & $(0.049)$ & $(0.064)$ & $(0.097)$ & $(0.102)$ \\
\hline \multicolumn{6}{|l|}{ Low education } \\
\hline \multirow[t]{2}{*}{ Formal } & 0.150 & 0.121 & 0.685 & 0.038 & 0.277 \\
\hline & $(0.035)$ & $(0.023)$ & $(0.072)$ & $(0.015)$ & $(0.068)$ \\
\hline \multirow[t]{2}{*}{ Informal } & 0.097 & 0.075 & 0.033 & 0.427 & 0.541 \\
\hline & $(0.036)$ & $(0.021)$ & $(0.016)$ & $(0.072)$ & $(0.071)$ \\
\hline \multirow[t]{2}{*}{ Not employed } & 0.754 & 0.804 & 0.022 & 0.039 & 0.940 \\
\hline & $(0.051)$ & $(0.031)$ & $(0.008)$ & $(0.014)$ & $(0.019)$ \\
\hline
\end{tabular}

Standard errors in parentheses. 
Table 10. Simulated Transition Probabilities (Females, random effects fixed)

\begin{tabular}{|l||c|c||c|c|c|}
\hline \hline \multicolumn{1}{|c||}{$j_{t}$} & \multicolumn{2}{c||}{$\operatorname{Prob}\left(j_{t}\right)$} & \multicolumn{3}{c|}{$\operatorname{Prob}\left(j_{2} \mid j_{1}\right)$} \\
\cline { 2 - 6 } & $t=1$ & $t=2$ & Formal & Informal & Not employed \\
\hline High education & \multirow{2}{*}{ Formal } & \multicolumn{1}{|c||}{} & & & \\
& 0.493 & 0.316 & 0.491 & 0.023 & 0.486 \\
Informal & $(0.167)$ & $(0.117)$ & $(0.063)$ & $(0.029)$ & $(0.070)$ \\
& 0.042 & 0.046 & 0.143 & 0.174 & 0.683 \\
Not-employed & $(0.045)$ & $(0.024)$ & $(0.136)$ & $(0.015)$ & $(0.133)$ \\
& 0.465 & 0.638 & 0.144 & 0.059 & 0.797 \\
& $(0.162)$ & $(0.113)$ & $(0.082)$ & $(0.083)$ & $(0.098)$ \\
\hline Low education & & & & & \\
Formal & 0.019 & 0.008 & 0.044 & 0.021 & 0.935 \\
& $(0.018)$ & $(0.006)$ & $(0.036)$ & $(0.013)$ & $0.040)$ \\
Informal & 0.058 & 0.037 & 0.008 & 0.106 & 0.887 \\
& $(0.041)$ & $(0.018)$ & $(0.007)$ & $(0.053)$ & $(0.053)$ \\
Not employed & 0.923 & 0.955 & 0.007 & 0.033 & 0.961 \\
& $(0.050)$ & $(0.020)$ & $(0.005)$ & $(0.015)$ & $(0.017)$ \\
\hline \hline
\end{tabular}

Standard errors in parentheses.

\section{Conclusions}

We have investigated labor market segmentation in urban Mexico by studying the wage differentials between the formal and informal sectors and the transition patterns between the labor market states formal sector employment, informal sector employment, and (for women only) non-employment. Mobility between these states is very large compared to other OECD countries. To explain the wage differentials between the two sectors and the labor market state of each individual in each quarter, a dynamic multinomial logit model with random effects for the choice and two linear dynamic random effect wage equations for the wages in the two sectors was formulated. We estimated this model for a Mexican panel data set covering the first quarter of 1992 to the first quarter of 1993.

Our findings on wage differentials are in line with the literature. The wages in both sectors increase with education, with the education effects stronger in the formal sector. Wages increase with age in the formal sector, but less so in the informal sector. Hence, wage differentials between formal and informal sector increase with education level and with age. We find no evidence of unobserved heterogeneity or an effect of the previous labor market state on the current wage.

The estimates show that the probability of formal sector employment strongly increases with the wage differential. For men, the probability of working in the informal sector decreases with the level of income of other family members. For women, other family income mainly increases the probability of not working. 
The simulated probabilities of transitions for individuals in different market conditions and for different individuals in the same period were compared. The results show that the main reason why men tend to stay in the same state is unobserved heterogeneity. For women on the other hand, we also find a substantial structural impact of the lagged labor market state. The high wage differentials for workers with high education level imply that the high educated more often work in the formal sector. High wages also induce more (female) nonworkers with high education level to work. For higher educated workers, we find low rates of formal sector turnover, while, due to the wage differentials, informal workers move to the formal sector quite often.

The main goal of the paper was to contribute to the debate in the literature on the role of the informal sector. For the reasons well documented in Maloney (1999), we cannot formally test whether either the staging hypothesis or the competitive labour market view is a realistic description of the actual labour markets in Mexico. Still, many of our findings strongly suggest that for the lower educated workers, the dualistic view of the labour market is not a good description. The same conclusion was also drawn by Maloney (1999). For the higher educated on the other hand, the urban labour markets in Mexico do have some important dualistic features. 


\section{References}

Calderón-Madrid, A. (1999), "Job Stability and Labor Mobility in Mexico During the 1990s'," working paper, Centro de Estudios Económicos, Mexico.

Fields, G. (1975), "Rural-Urban Migration, urban Unemployment and Underemployment, and job search activity in LDCs," Journal of Development Economics 2, 165-187.

Fleck, S. and C. Sorrentino (1994), "Employment and Unemployment in Mexico's labor force," Monthly Labor Review 117(11), 3-31.

Gong, X., A. van Soest, and E. Villagomez (2000), "Mobility in the Urban Labor Market: a panel data analysis for Mexico," CentER Discussion Paper, Tilburg University.

Hajivassiliou, V.A. and P.A. Ruud (1994), "Classical estimation methods for LDV models using simulation," in: Robert F. Engle and Daniel L. McFadden (eds.), Handbook of Econometrics, vol. IV, North-Holland, New York, 2384-2443.

Heckman, J. (1981a), "Statistical Models for Discrete Panel Data," in Structural Analysis of Discrete Data with Econometric Applications, Manski, C. and D. McFadden (eds.), MIT Press, London, 114-178.

Heckman, J. (1981b), "The incidental Parameters Problem and the Problem of Initial Conditions in Estimating a Discrete Time-Discrete Data Stochastic Process," in Structural Analysis of Discrete Data with Econometric Applications, Manski, C. and D. McFadden (eds.), MIT Press, London, 179-195.

Heckman, J. and G. Sedlacek (1985), "Heterogeneity, aggregation and market wage functions: an empirical model of self-selection in the labor market," Journal of Political Economy 93, 1077-1125.

Hollon, C. (1996), "Individual Employee Employment Security under Mexican Federal Labor Law," Labor Law Journal, October, 648-655.

Magnac, Th. (1991), "Segmented or Competitive Labor Markets," Econometrica 59, 165-187.

Maloney, W. (1999), "Does Informality Imply Segmentation in Urban Labor Markets? Evidence from Sectoral Transitions in Mexico," The World Bank Economic Review 13(2), 275-302.

Martin, P. (1999), "Trade and Migration: The Mexican-US Experience," mimeo, University of California, Davis.

Mellow, W. (1982), "Employer Size and Wages," Review of Economics and Statistics 64(3), 495-501

Polachek, S. and W. Siebert (1996), The economics of Earnings, Cambridge University Press, Cambridge.

Pradhan, M. \& A. van Soest (1995), "Formal and informal sector employ- 
ment in Urban Areas of Bolivia," Labor Economics 2, 275-297.

Pradhan, M. and A. van Soest (1997), "Household labor supply in Urban Areas of Bolivia," Review of Economics and Statistics 79, 300-310.

Siebert, S. and J. Addison (1991), "Internal Labour Markets: Causes and Consequences," Oxford Review of Economic Policy 7, 76-92.

Stigler, G. (1962), "Information in the Labour Market," Journal of Political Economy 70, 94-105.

Strassmann, W. (1987), "Home-based Enterprises in cities in developing countries," Economic Development and Cultural Change 36, 121-144.

Thomas, J. (1992), "Informal Economic Activity," in LSE Handbook in Economics, Harvester Wheatsheaf, Hertfordshire.

Villagomez, E (1996), "Informal Markets: A Model of Household Labor Supply," working paper, Universidad de Alcala de Henares.

Villagomez, E (1998), "Mobility between the formal and informal sector: A panel data analysis for five Mexican cities," working paper, Universidad de Alcala de Henares.

Zelek, M., \& O. de la Vega (1992), "An outline of Mexican Labor law," Labor Law Journal, July, 466-470. 


\section{Appendix:}

Table A1. Variable definitions

\begin{tabular}{l|l}
\hline \hline Variables & Explanation \\
\hline Child & Number of children younger than 6 years old \\
Adults & Number of family members older than 11 years old \\
Lowedu & Age of the individual \\
Medu & No education or primary school education (0-6 years) \\
Hedu & Univ. or vocational education after Senior school (12+ years) \\
Othinc & Real incomes from other family members (in pesos of July, 1995) \\
JuaTij & Ciudad Juarez and Tijuana \\
Guada & Guadalajara \\
Mont. & Monterrey \\
Mex. City & Mexico City \\
Married & Married persons \\
Nmar & Single or divorced \\
T1 & Time dummy: 1 if the first quarter \\
T2 & Time dummy: 1 if the second quarter \\
T3 & Time dummy: 1 if the third quarter \\
T4 & Time dummy: 1 if the fourth quarter \\
T5 & Time dummy: 1 if the fifth quarter \\
Form. & formal sector workers \\
Infor. & Informal sector workers \\
Noem. & being not employed \\
\hline \hline
\end{tabular}

Table A2. Sample statistics

\begin{tabular}{l||l|l}
\hline \hline Variables & Men & Women \\
\hline Child & $0.750(0.87)$ & $0.660(0.85)$ \\
Adults & $3.312(1.70)$ & $3.287(1.76)$ \\
Age & $38.844(10.86)$ & $38.670(12.13)$ \\
Lowedu & 0.441 & 0.554 \\
Medu & 0.370 & 0.375 \\
Hedu & 0.189 & 0.071 \\
Othinc & $950.7(1643)$ & $2373.1(2501)$ \\
JuaTij & 0.156 & 0.331 \\
Guada & 0.181 & 0.147 \\
Mont. & 0.208 & 0.211 \\
Mex. City & 0.321 & 0.311 \\
Married & 0.948 & 0.830 \\
\hline \hline
\end{tabular}

Standard deviations in parentheses. 
Figure 1. Comparison of real log wages in formal and informal sector (Men)

High \& Middle education received

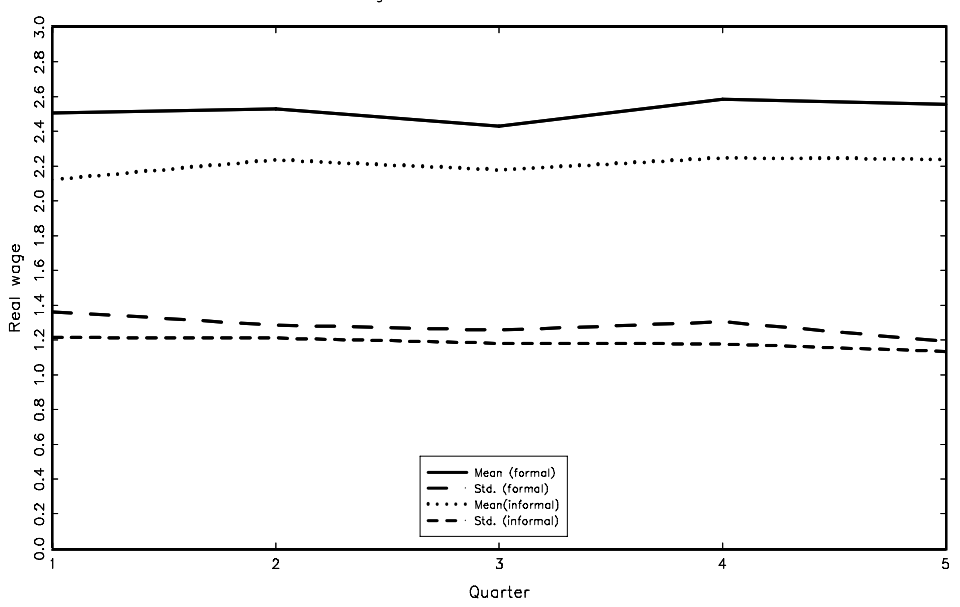

Low or no education received

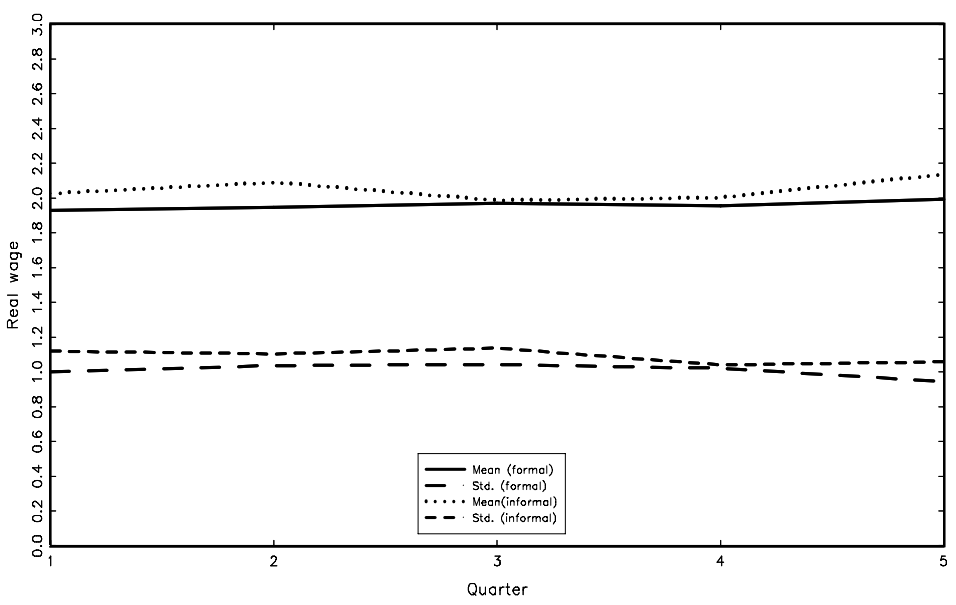


Figure 2. Comparison of real log wages in formal and informal sector (women)

High \& Middle education received

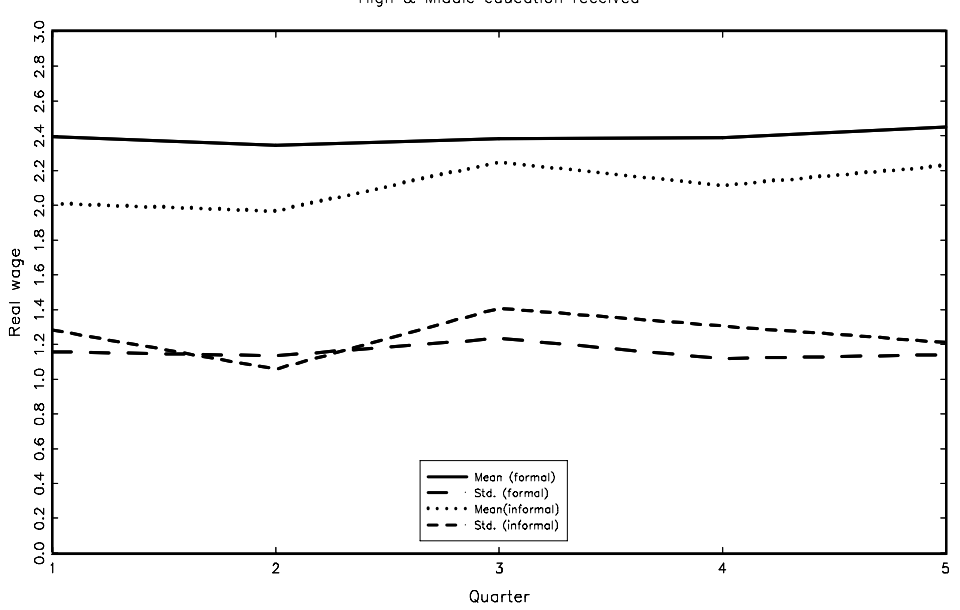

Low or no education received

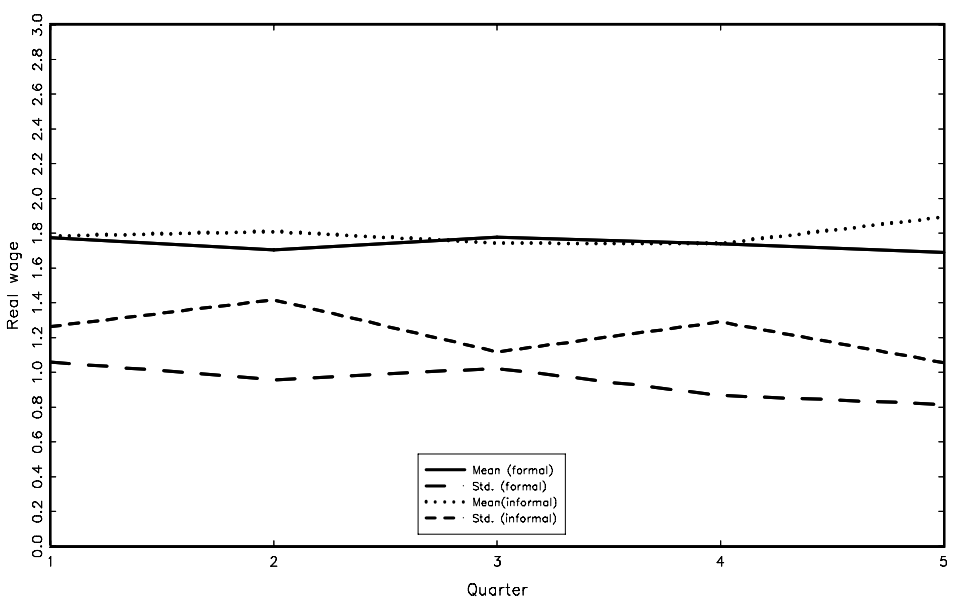


Figure 3. Nonparametric regressions of wage differentials against age (men)

Panel 1. formal to formal

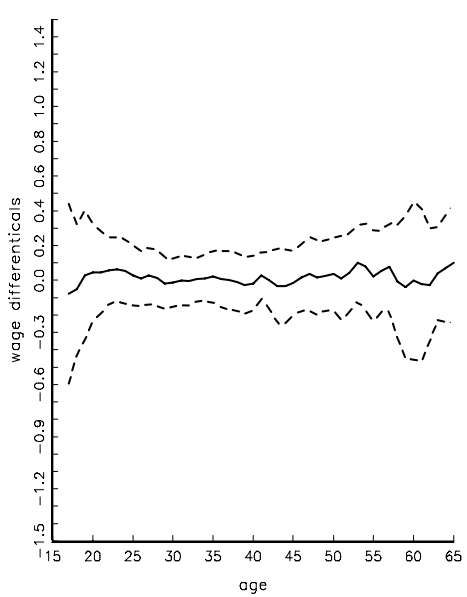

Panel 3. informal to formal

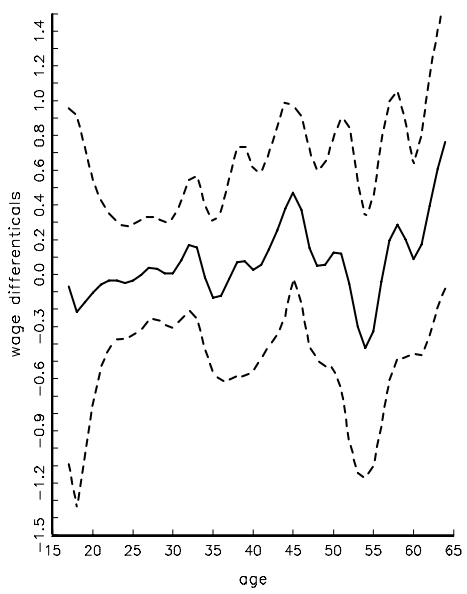

Panel 2. formal to informa

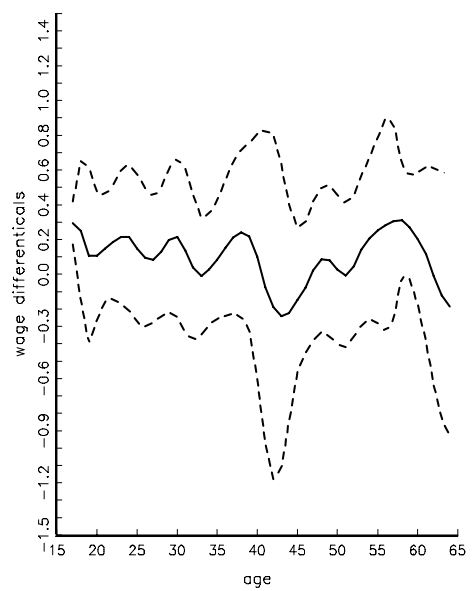

Panel 1. informal to informal

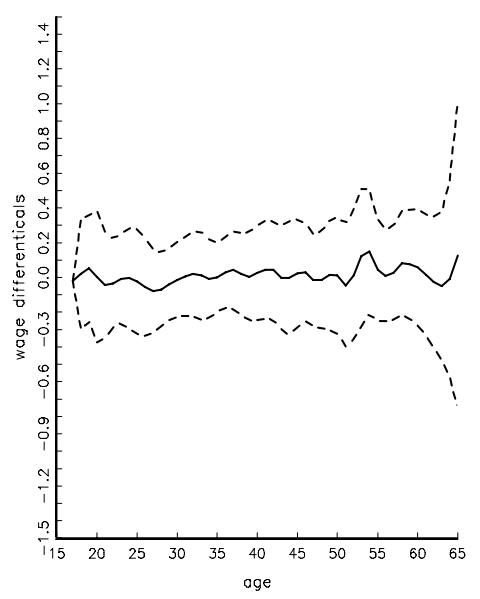


Figure 4. Nonparametric regressions of wage differentials against age (women)
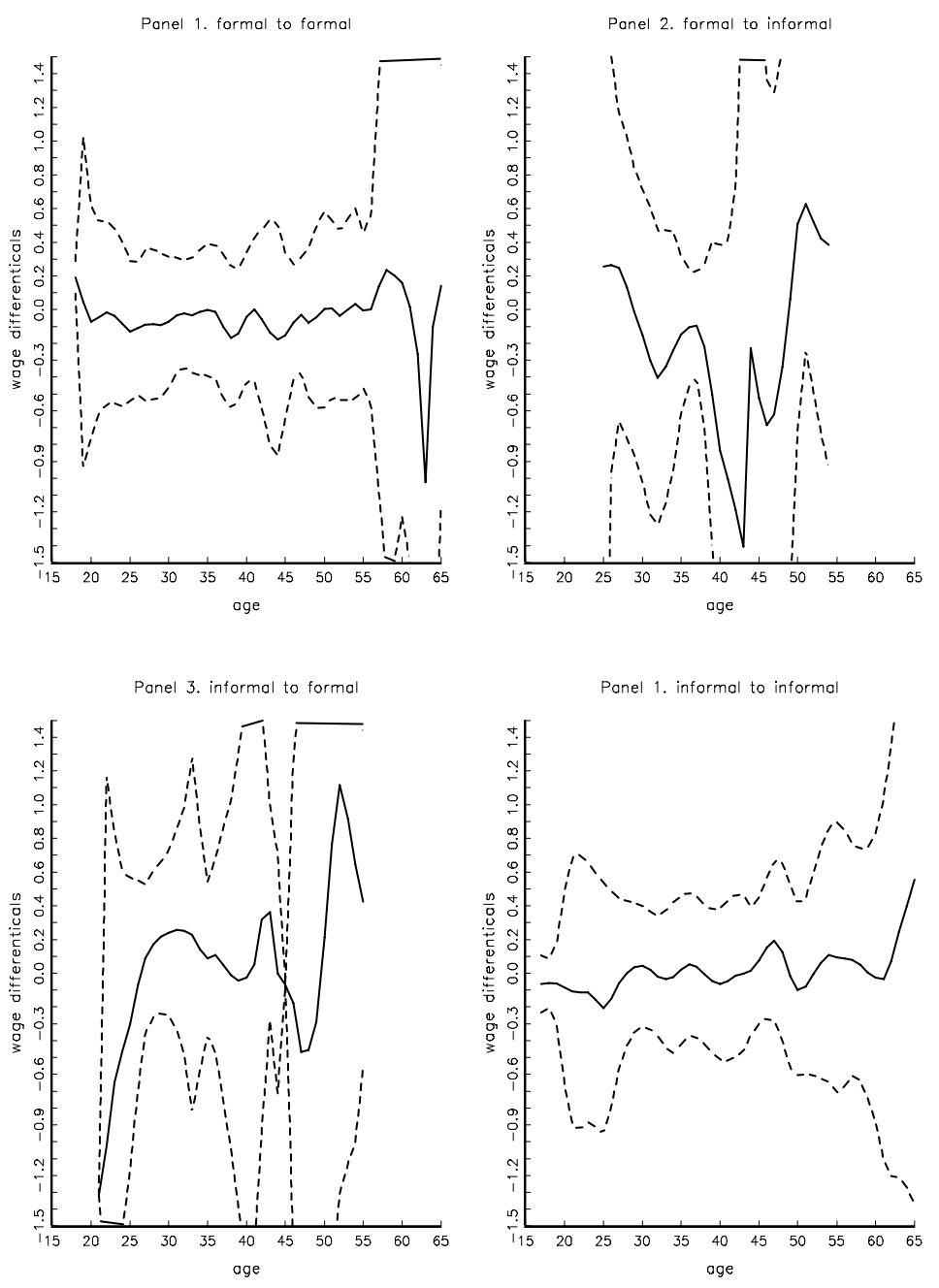
Figure 5. Wage differentials between formal and informal sector (men)

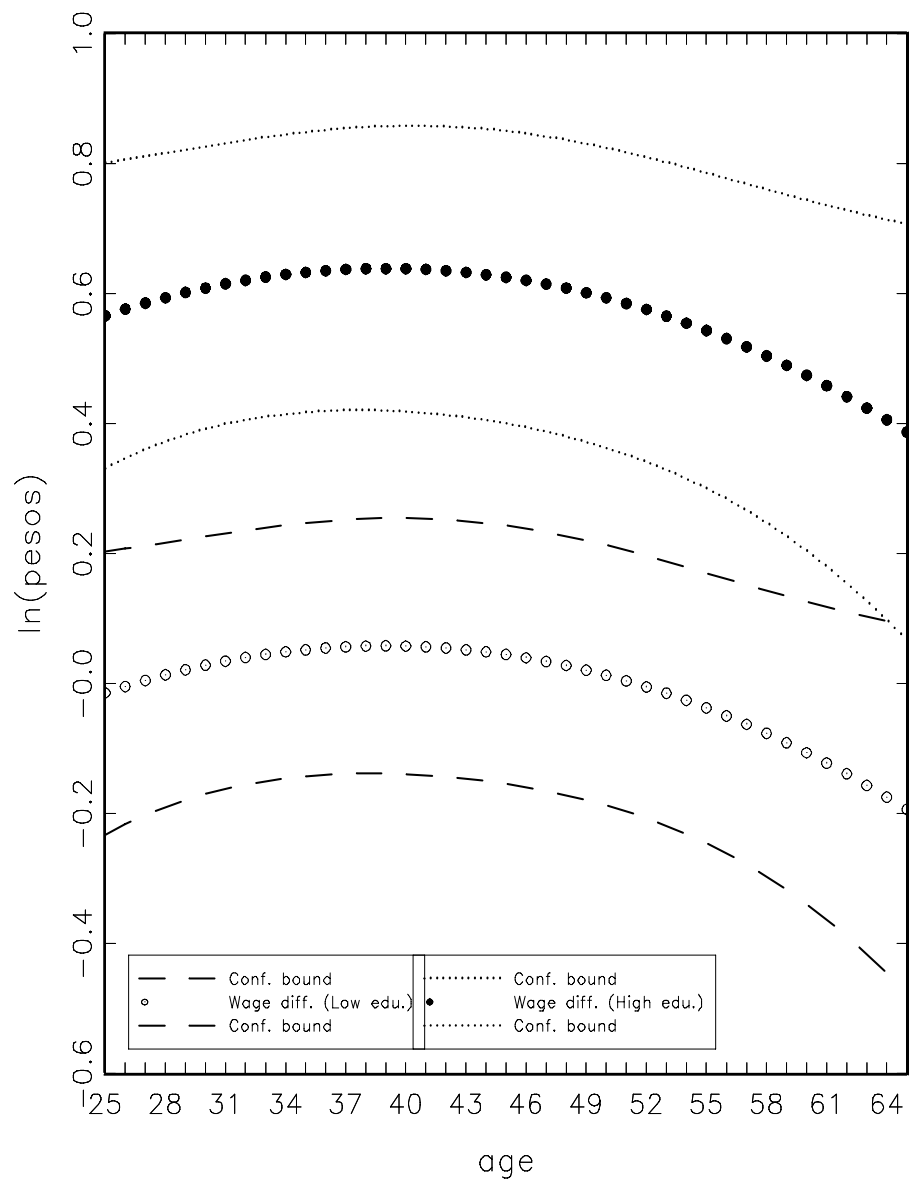


Figure 6. Wage differentials between formal and informal sector (women)

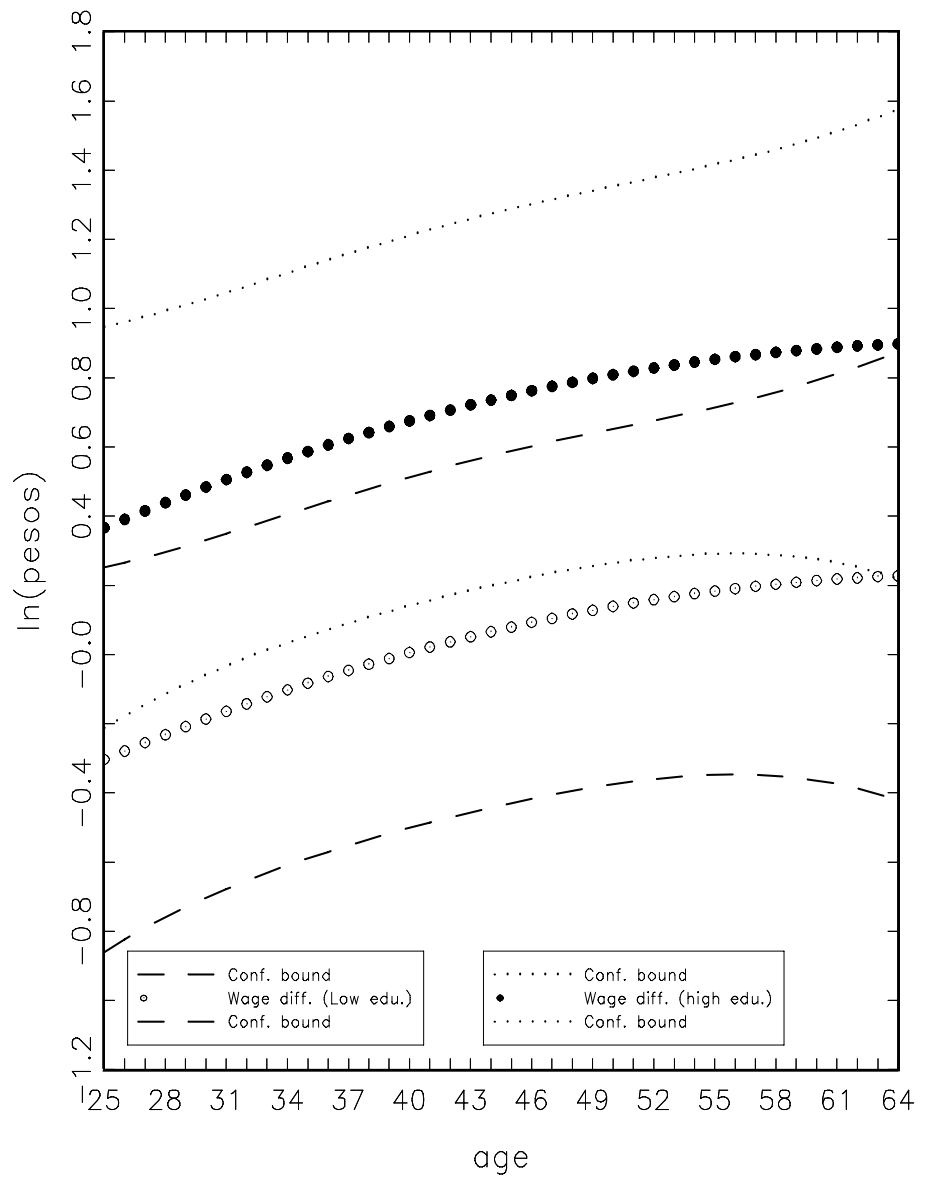




\section{IZA Discussion Papers}

No Author(s)

250 T. J. Hatton

J. G. Williamson

251

R. Yemtsov

252

R. Yemtsov

253

R. Yemtsov

254 H. Gersbach

A. Schniewind

255 H. Gersbach

A. Schniewind

256

T. Boeri

H. Brücker

257

T. Boeri

258 M. Rosholm

K. Scott

L. Husted

259 A. Ferrer-i-Carbonell

B. M.S. van Praag

260 P. Cahuc

F. Postel-Vinay

261 M. Lindahl

262

M. Lindahl

263 N. Datta Gupta

N. Smith
Titel

Area

Date

Demographic and Economic Pressure on

1

$01 / 01$

Emigration out of Africa

Labor Markets, Inequality and Poverty in Georgia

4

$01 / 01$

Inequality and Income Distribution in Georgia

4

01/01

Living Standards and Economic Vulnerability in 4 Turkey between 1987 and 1994

$01 / 01$

Learning of General Equilibrium Effects and the 3 Unemployment Trap

$02 / 01$

Product Market Reforms and Unemployment in 3 Europe

$02 / 01$

Eastern Enlargement and EU-Labour Markets: 2

Perceptions, Challenges and Opportunities

Transition with Labour Supply

4

$02 / 01$

The Times They Are A-Changin':

$02 / 01$

Organizational Change and Immigrant

1

Employment Opportunities in Scandinavia

Poverty in the Russian Federation

4

$02 / 01$

Temporary Jobs, Employment Protection and

$1 / 3$

$02 / 01$

Labor Market Performance

Home versus School Learning:

5

$02 / 01$

A New Approach to Estimating the Effect of

Class Size on Achievement

Summer Learning and the Effect of Schooling:

5

02/01 Evidence from Sweden

Children and Career Interruptions:

5

$02 / 01$ 
S. Vroman

283 M. Hagedorn

A. Kaul Elites

V. Reinthaler

Is There a Glass Ceiling in Sweden? to Internal Promotion for Young U.S. Men and Women
289
L. Cameron
D. A. Cobb-Clark

D. A. Cobb-Clark

M. D. Connolly

C. Worswick

Old-Age Support in Developing Countries: Analysis of Census Data

Between-group Competition in the Labor Market and the Rising Returns to Skill: US and France 1964-2000 

ment when Search Frictions Interact with Intrafirm Bargaining 

Monetary Appraisal 
